\title{
CD22 Regulates Adaptive and Innate Immune Responses of B Cells
}

\author{
Norihito Kawasaki Christoph Rademacher James C. Paulson \\ Department of Chemical Physiology, The Scripps Research Institute, La Jolla, Calif., USA
}

\begin{abstract}
Key Words
CD22 - Sialic acid binding immunoglobulin-like lectin • Toll-like receptors $\cdot B$ cells $\cdot$ Self nonself recognition
\end{abstract}

\begin{abstract}
$B$ cells sense microenvironments through the $B$ cell receptor (BCR) and Toll-like receptors (TLRs). While signals from BCR and TLRs synergize to distinguish self from nonself, inappropriate regulation can result in development of autoimmune disease. Here we show that CD22, an inhibitory co-receptor of $B C R$, also negatively regulates TLR signaling in $B$ cells. $\mathrm{CD} 22$-deficient $\left(\mathrm{Cd} 22^{--}\right) \mathrm{B}$ cells exhibit hyperactivation in response to ligands of TLRs 3, 4 and 9. Evidence suggests that this results from impaired induction of suppressors of cytokine signaling 1 and 3, well-known suppressors of TLR signaling. Antibody-mediated sequestration of CD22 on wild-type (WT) B cells augments proliferation by TLR ligands. Conversely, expression of CD22 in a $C d 22^{-/-} B$ cell line blunts responses to TLR ligands. We also show that lipopolysaccharide-induced transcription by nuclear factor- $\kappa B$ is inhibited by ectopic expression of CD22 in a TLR4 reporter cell line. Taken together, these results suggest that negative regulation of TLR signaling is an intrinsic property of CD22. Since TLRs and BCR activate B cells through different signaling pathways, and are differentially localized in B cells, CD22 exhibits a broader regulation of receptors that mediate adaptive and innate immune responses of $B$ cells than previously recognized.

Copyright $\odot 2010$ S. Karger AG, Basel
\end{abstract}

\section{Introduction}

CD22 is a sialic acid binding immunoglobulin-like lectin (Siglec) expressed on B cells, which is known for its role in regulation of $\mathrm{B}$ cell receptor (BCR) $[1,2]$. The ligand recognized by $\mathrm{CD} 22$ is a sialic acid containing glycan found on mammalian cells that is absent on most pathogens [1]. Simultaneous presentation of antigen and CD22 ligand results in coligation of CD22 with the BCR and inhibition of BCR signaling [2-5]. Thus, CD22 has been proposed to aid $\mathrm{B}$ cells in distinguishing self from nonself [3-5].

Recent studies demonstrate that in B cells, Toll-like receptors (TLRs) play an important role in modulation of their function in an immune response [6]. Although not required for induction of humoral immunity, TLR signals independent of BCR ligation induce and enhance proliferation, antigen presentation and immunoglobulin production in B cells [6-10]. However, it has also been suggested that the synergy between BCR and TLR7 and 9 in response to nucleotide-containing self-antigens might result in the aberrant activation of autoreactive $B$ cells $[6,11]$.

Here we report that $C d 22^{-/-} \mathrm{B}$ cells exhibit hyperactivation in response to ligands of several TLRs including TLR3, 4 and 9 and that in wild-type (WT) B cells, antibody-mediated sequestration of CD22 from TLRs augments the proliferation by TLR ligands. We also demonstrate that in $\mathrm{Cd} 22^{-/-} \mathrm{B}$ cells, induction of suppressors of

\section{KARGER}

(C) 2010 S. Karger AG, Basel

Fax +4161306 1234

E-Mail karger@karger.ch

www.karger.com
Accessible online at: www.karger.com/jin
Dr. James C. Paulson

Department of Chemical Physiology, The Scripps Research Institute 10550 N. Torrey Pines Road, MEM L71

La Jolla, CA 92037 (USA)

Tel. +1 858784 9634, Fax +1 858784 9690, E-Mail jpaulson@ scripps.edu 
cytokine signaling (SOCS) 1 and 3, well-documented suppressors of TLR signaling [12, 13], is impaired and that lipopolysaccharide (LPS) induced activation of transcription by nuclear factor- $\mathrm{B}$ (NF- $\mathrm{\kappa B})$, which is a hallmark of TLR signaling, is inhibited by the expression of CD22 in a TLR4 reporter cell line. These observations document a broader role for CD22 in regulation of receptors that mediate $\mathrm{B}$ cell signaling that distinguish self and nonself.

\section{Materials and Methods}

\section{Mice}

C57BL/6J and $C d 22^{-/-}$mice (a generous gift from Dr. Lars Nitschke, University of Erlangen, Germany) were maintained in pathogen-free conditions at The Scripps Research Institute breeding facility and were used in accordance to the guidelines of the Institutional Animal Care Committee at the National Institutes

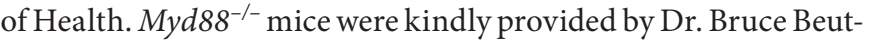
ler (The Scripps Research Institute, La Jolla, Calif., USA).

\section{Retrovirus Vector and Cell Lines}

The retrovirus vector pMXs-IRES-EGFP (pMXs-IG) encoding the cytoplasmic domain of murine $\mathrm{CD} 3 \zeta$ and the retroviruspackaging cell line Plat-E were provided by Dr. Kazuo Yamamoto (University of Tokyo, Tokyo, Japan) by permission of Dr. Toshio Kitamura (University of Tokyo, Tokyo, Japan). Plat-E cells were maintained in Dulbecco's modified Eagle's medium (Invitrogen, Carlsbad, Calif., USA) supplemented with $10 \%$ heat-inactivated fetal calf serum (FCS), $100 \mathrm{U} / \mathrm{ml}$ penicillin, $100 \mu \mathrm{g} / \mathrm{ml}$ streptomycin, $2 \mathrm{mM}$ glutamine, $50 \mu \mathrm{M} 2$-mercaptoethanol, $1.0 \mu \mathrm{g} / \mathrm{ml}$ of pu-

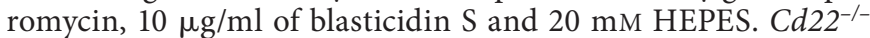
murine B cell line J2-44 cells were kindly provided by Dr. Henry H. Wortis (Tufts University, Boston, Mass., USA) and maintained in RPMI 1640 medium (Invitrogen) supplemented with 10\% heatinactivated FCS, $100 \mathrm{U} / \mathrm{ml}$ penicillin, $100 \mu \mathrm{g} / \mathrm{ml}$ streptomycin, $2 \mathrm{~mm}$ glutamine and $50 \mu \mathrm{M} 2$-mercaptoethanol. HEK293 cells expressing mTLR4/MD2-CD14 were obtained from Invivogen (San Diego, Calif., USA) and maintained in the same medium with Plat-E with $50 \mu \mathrm{g} / \mathrm{ml}$ of hygromycin B instead of puromycin.

\section{Isolation of Splenic B Cells}

Splenic B cells were isolated from mouse spleens by negative selection using MACS mouse B cell isolation kit (Miltenyi Biotech, Auburn, Calif., USA) or EasySep (StemCell Technologies, Vancouver, B.C., Canada). The purity of isolated B cells was assessed by the staining of isolated cells with anti-mouse CD19 $\mathrm{mAb}$ (1D3; BD Biosciences, San Jose, Calif., USA) and was more than 94\% throughout this study.

\section{B Cell Proliferation Assay}

Purified B cells were suspended at $1.0 \times 10^{7}$ cells $/ \mathrm{ml}$ in Hank's balanced salt solution (Invitrogen) containing $3 \%$ heat-inactivated FCS and 4-6 $\mu \mathrm{M}$ of carboxyfluorescein diacetate succinimidyl ester (Invitrogen) for $7 \mathrm{~min}$ at $25^{\circ} \mathrm{C}$. Carboxyfluorescein succinimidyl ester (CFSE)-labeled B cells were added in 96-well flat-bottom plate at $2.0 \times 10^{5}$ cells/well in the $200 \mu \mathrm{l}$ of RPMI medium
(Invitrogen) supplemented with 10\% heat-inactivated FCS, $2 \mathrm{~mm}$ glutamine, $100 \mathrm{U} / \mathrm{ml}$ penicillin, $100 \mu \mathrm{g} / \mathrm{ml}$ streptomycin, $1 \mathrm{mM}$ nonessential amino acid, $1 \mathrm{mM}$ sodium pyruvate and $50 \mu \mathrm{M}$ 2-melcaptoethanol. For the BCR stimulation, goat $\mathrm{F}\left(\mathrm{ab}^{\prime}\right)_{2}$ antimouse IgM (Jackson Immunoresearch, West Grove, Pa., USA) was added to each well. For TLR stimulation, poly(I:C), LPS and CpG1826 (Invivogen) were added. All culture was done with triplicate samples. The cells were allowed to proliferate for 2-3 days. Cells were then harvested and analyzed by flow cytometry with the exclusion of dead cells using $1 \mu \mathrm{g} / \mathrm{ml}$ of propidium iodide staining. More than $2.5 \times 10^{4}$ total counts were acquired in FACS Caliber (BD Biosciences) and analyzed with Flowjo (Tree Star, San Carlos, Calif., USA). For the experiment using immobilized antibodies, 96-well ELISA plate was first coated with $20 \mu \mathrm{g} / \mathrm{ml}$ of neutravidin (Pierce, Rockford, Ill., USA), then washed with phosphate-buffered saline (PBS) and added with biotinylated antiCD22 (Cy34.1; BD Biosciences) or mouse IgG1 isotype-matched control antibody (Biolegend, San Diego, Calif., USA). Then wells were washed with PBS and added with B cells in the presence of LPS, CpG or anti-IgM. To count the living cell number, $1.0 \times 10^{4}$ of Calibrite beads (BD Biosciences) was added to each well before harvesting cells. The living cell number was calculated by the formula: living cells number in the well $=$ the number of living cells acquired $\times$ the number of beads acquired $/ 1.0 \times 10^{4}$.

\section{Activation Marker Expression Analysis}

Purified B cells or J2-44 cells were cultured for 2 days with or without stimuli as described above. Cells were then harvested, washed with Hank's balanced salt solution containing $0.1 \%$ BSA, $1 \mathrm{mM} \mathrm{MgSO}_{4}, 1.3 \mathrm{mM} \mathrm{CaCl}_{2}$ and $0.1 \% \mathrm{NaN}_{3}$ (FACS buffer). Cells were then blocked with anti-mouse CD16/32 (2.4G2; BD Biosciences), and stained with anti-CD86 (GL1; eBiosicence, San Diego, Calif., USA) and MHC class II I-A b (AF6-120.1; BD Biosciences). The stained cells were washed with FACS buffer and analyzed by flow cytometry as described above.

\section{TLR9 Expression Analysis}

Purified B cells were fixed with 3\% parafolmaldehyde in PBS for $10 \mathrm{~min}$ at $25^{\circ} \mathrm{C}$. Then cells were permeabilized with PBS containing $0.1 \%$ saponin (Sigma-Aldrich, St. Louis, Mo., USA), 1\% BSA and $0.05 \% \mathrm{NaN}_{3}$ (PBS-S). Fixed and permeabilized cells were blocked with $1 \%$ normal rat serum in PBS-S and stained with anti-TLR9 Ab (IMG-431; Imgenex, San Diego, Calif., USA) followed by phycoerythrin-labeled goat $\mathrm{F}\left(\mathrm{ab}^{\prime}\right)_{2}$ anti-rabbit IgG (Southern Biotech, Birmingham, Ala., USA). The stained cells were washed with PBS-S and analyzed by flow cytometry.

\section{Real-Time PCR}

Total RNA was isolated from WT and $\mathrm{Cd} 22^{-/-} \mathrm{B}$ cells with TRIzol reagent (Invitrogen). Random hexamer-primed firststrand cDNA was synthesized from DNase-treated total RNA by reverse transcription using Superscript III (Invitrogen). SYBR Green-based real-time PCR was performed using the DyNAmo SYBR Green qPCR Kit (Finnzymes Oy, Espoo, Finland). Signals were normalized to $\beta$-actin and normalized data were used to quantitate relative levels of TLR3 and 4 by using $\Delta \Delta$ Ct analysis. Primers used were below: $5^{\prime}$-atgatacagggattgcaccc- $3^{\prime}$ and $5^{\prime}$-atagggacaaaagtccccca- $3^{\prime}$ for TLR3, 5'-ttcacctctgccttcactaca- $3^{\prime}$ and $5^{\prime}$-gggacttctcaaccttctcaa- $3^{\prime}$ for TLR4, 5'-ccgtgggtcgcgagaac- ${ }^{\prime}$ and $5^{\prime}$-aactcaggtagtcacggagtaccg-3' for SOCS1, $5^{\prime}$-tcccatgec- 
gctcacag- $3^{\prime}$ and $5^{\prime}$-acaggaccagttccaggtaattg for SOCS3 [14], and $5^{\prime}$-tgggacgacatggagaagatctggc- $3^{\prime}$ and $5^{\prime}$-tacgaccagaggcatacagggacagc- $3^{\prime}$ for $\beta$-actin.

Transduction of the J2-44 Cell Line with Murine CD22

cDNA for murine CD22 was subcloned into the pMXs-IG vector. The CD22-pMXs-IG vector and the translation-incompatible CD3 3 -pMXs-IG vector were used for transduction of the J2-44 cell line to establish CD22/J2-44 cells and Mock/J2-44 cells, respectively. Briefly, the retrovirus packaging cell line Plat-E were transfected with the pMXs-IG vectors by Lipofectamin 2000 (Invitrogen). After 2 days, the culture supernatant was harvested and added to $\mathrm{J} 2-44$ cells with $8 \mu \mathrm{g} / \mathrm{ml}$ of Polybrane (Millipore, Bedford, Mass., USA). J2-44 cells expressing EGFP were sorted to more than $95 \%$ by the FACSVantage SE (BD Biosciences).

\section{Western Blot}

Purified B cells $\left(2.2 \times 10^{7}\right.$ cells $)$ were rested for $2 \mathrm{~h}$ before stimulation in $1 \mathrm{ml}$ of the medium. Cells were stimulated with 10 $\mu \mathrm{g} / \mathrm{ml}$ anti-mouse IgM and $1 \mu \mathrm{M} \mathrm{CpG}$ for the indicated time period. Stimulation was stopped by fast spin down and direct lysis in $80 \mu \mathrm{l}$ of ice-cold lysis buffer containing $50 \mathrm{~mm}$ Tris- $\mathrm{HCl} \mathrm{pH}$ 8.0, $150 \mathrm{~mm} \mathrm{NaCl}, 1 \%$ Triton X-100, protease inhibitors set III (Calbiochem, San Diego, Calif., USA), and phosphatase inhibitor set II (Calbiochem) for $30 \mathrm{~min}$ on ice. After cell debris was removed by spin down at $13,000 \mathrm{~g}$ at $4^{\circ} \mathrm{C}$ for $15 \mathrm{~min}$, proteins in the supernatant were separated by polyacrylamide gel electrophoresis using $4-12 \% 1$-mm NuPAGE gels $\left(5 \times 10^{6}\right.$ cells/lane) (Invitrogen) and transferred to nitrocellulose membrane (Pall Corporation, Pensacola, Fla., USA). The membrane was blocked with 5\% skim milk (LabScientific, Livingstone, N.J., USA) in Tris-buffered saline $\mathrm{pH} 7.4$ containing $0.005 \%$ Tween 20 (TBS-T) and probed with 1:1,000 polyclonal anti-I $\mathrm{B} \alpha$ antibody (cat. 9242; Cell Signaling, Danvers, Mass., USA), 1:250 polyclonal anti-IRAK-1 antibody (cat. H-273, Santa Cruz Biotechnology, Santa Cruz, Calif., USA), 1:1,000 monoclonal phospho-p38 (Thr180/Thy182) antibody (cat. AF869; R\&D Systems), 1:500 polyclonal phospho-JNK (Thr221/ Tyr223) (cat. 07-175; Upstate Biotechnology, New York, N.Y., USA) or 1:250 polyclonal anti-actin antibody (cat. I19; Santa Cruz Biotechnology) for $16 \mathrm{~h}$ at $4^{\circ} \mathrm{C}$. The membrane was washed with TBS-T and incubated with 1:20,000 donkey anti-rabbit IgG peroxidase conjugate (Jackson Immunoresearch) for IкB and IRAK1 or 1:20,000 rabbit anti-goat IgG peroxidase conjugate (Jackson Immunoresearch) for actin for $1 \mathrm{~h}$ at $25^{\circ} \mathrm{C}$. After washing with TBS-T, signals were developed using an ECL Plus Western blot detection system (GE Healthcare).

\section{$N F-\kappa B$ Reporter Assay}

HEK293 cells expressing mTLR4/MD2-CD14 (Invivogen) were seeded at $4.0 \times 10^{4}$ cells/well in 96-well plate and transfected with $200 \mathrm{ng}$ of the reporter plasmid pNiFty2SEAP which encodes NF- $\kappa \mathrm{B}$-inducible soluble form of embryonic alkaline phosphatase (AP) with $120 \mathrm{ng}$ of either mCD22-pcDNA3.1(+) or empty vector. After $24 \mathrm{~h}$ incubation, $10 \mu \mathrm{g} / \mathrm{ml}$ of LPS were added to wells. After $16 \mathrm{~h}$ incubation, AP activity in the supernatant was measured following the manufacturer's instruction.

$N F-\kappa B$ DNA Binding Assay

Nuclear extracts of $C d 22^{-/-}$and WT B cells were prepared using the Nuclear Extract Kit (Active Motif, Carlsbad, Calif., USA) following the manufacturer's instructions. Protein concentration was determined by BCA assay (Pierce) and $9.4 \mu \mathrm{g}$ of nuclear extracts per well were subjected to ELISA using oligonucleotides containing the NF- $\mathrm{BB}$-binding site and specific antibodies to determine which NF- $\kappa \mathrm{B}$ subunits within the bound complexes were active (TransAM NF-кB Family Kit; Active Motif). Assays were run in triplicates.

\section{Results and Discussion}

Although CD22 is known as a regulator of the BCR, several earlier reports showed that B cells from $C d 22^{-/-}$ mice exhibit hyperproliferation in response to LPS, a ligand of TLR4 [15-17], and more recently to ligands to TLR7 and TLR9 [18], which are localized to endosomes. However, the significance of these findings has been largely overlooked $[1,2]$. CD22 is known to undergo constitutive endocytosis [19], and is therefore localized to both the cell surface and endosomes, consistent with a potential role in regulation of these TLRs. As shown in figure 1, CFSE-labeled B cells from $C d 22^{-/-}$mice exhibited hyperproliferation relative to WT B cells in response to ligands for TLRs 3, 4 and 9 (poly(I:C), LPS and CpG, respectively). Paradoxically, $C d 22^{-/-} \mathrm{B}$ cells showed slightly impaired proliferation in response to anti-IgM, consistent with several previous reports [15-17]. Proliferation by LPS and CpG was completely MyD88 dependent, consistent with known dependence on MyD88 for signaling mediated by TLR4 and TLR9 (fig. 1b) [20], while signaling in response to poly(I:C) was unaffected by the MyD88 deficiency, since TLR3 mediates signaling through the TRIF pathway [20]. The CFSE dilution was concomitant with an increase in the absolute number of living $C d 22^{-/-} \mathrm{B}$ cells at 3 days culture (fig. 1c). The augmented proliferation of $C d 22^{-/-} \mathrm{B}$ cells was accompanied by increased induction of the co-stimulatory molecule CD86 and MHC class II, required for activation of T cells (fig. 2). The augmented TLRs 3, 4 and 9 signaling in $C d 22^{-/-} \mathrm{B}$ cells was not a result of increased expression of TLRs, since expression of TLR3 and 9 in $C d 22^{-/-} \mathrm{B}$ cells was similar to that in WT B cells, and $C d 22^{-/-} \mathrm{B}$ cells express TLR4 at a lower level than WT B cells (fig. 3; online suppl. fig. 1, www.karger.com/doi/10.1159/000322375). Taken together, these data indicate that CD22 deficiency affects both MyD88-dependent and MyD88-independent TLR signaling in B cells.

Several approaches were taken to investigate the possibility that the increased TLR signaling might be an indirect effect of CD22 on B cell development. We first examined the impact of the expression of CD22 on TLR 

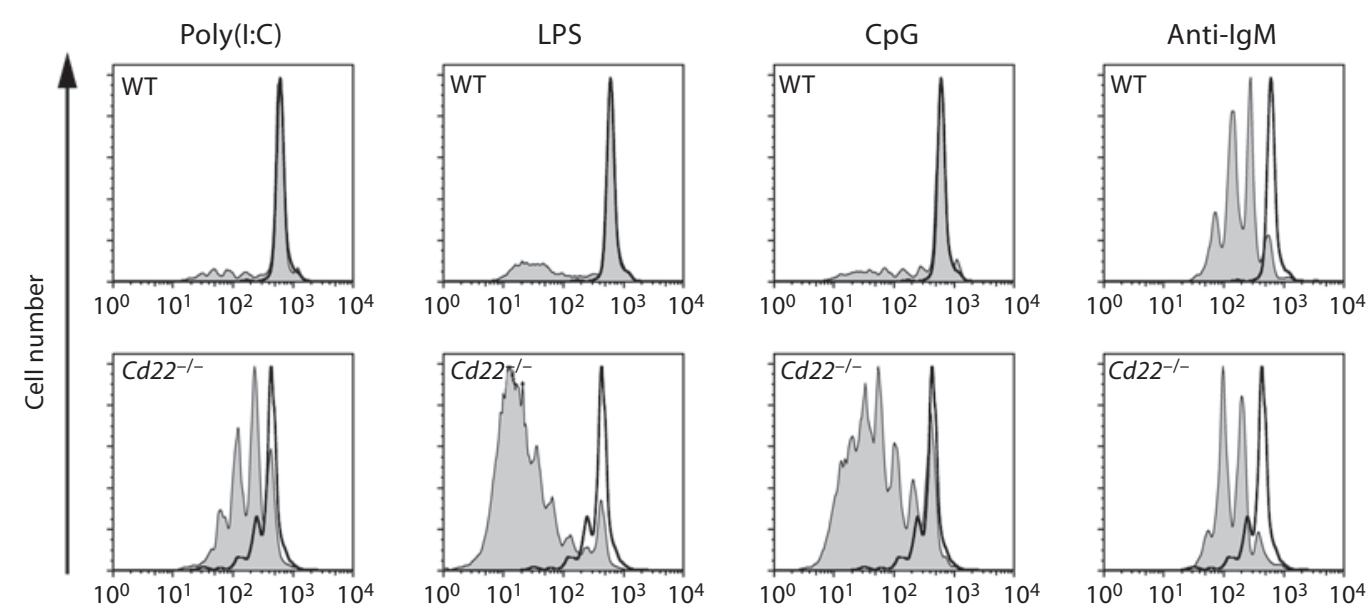

a

CFSE
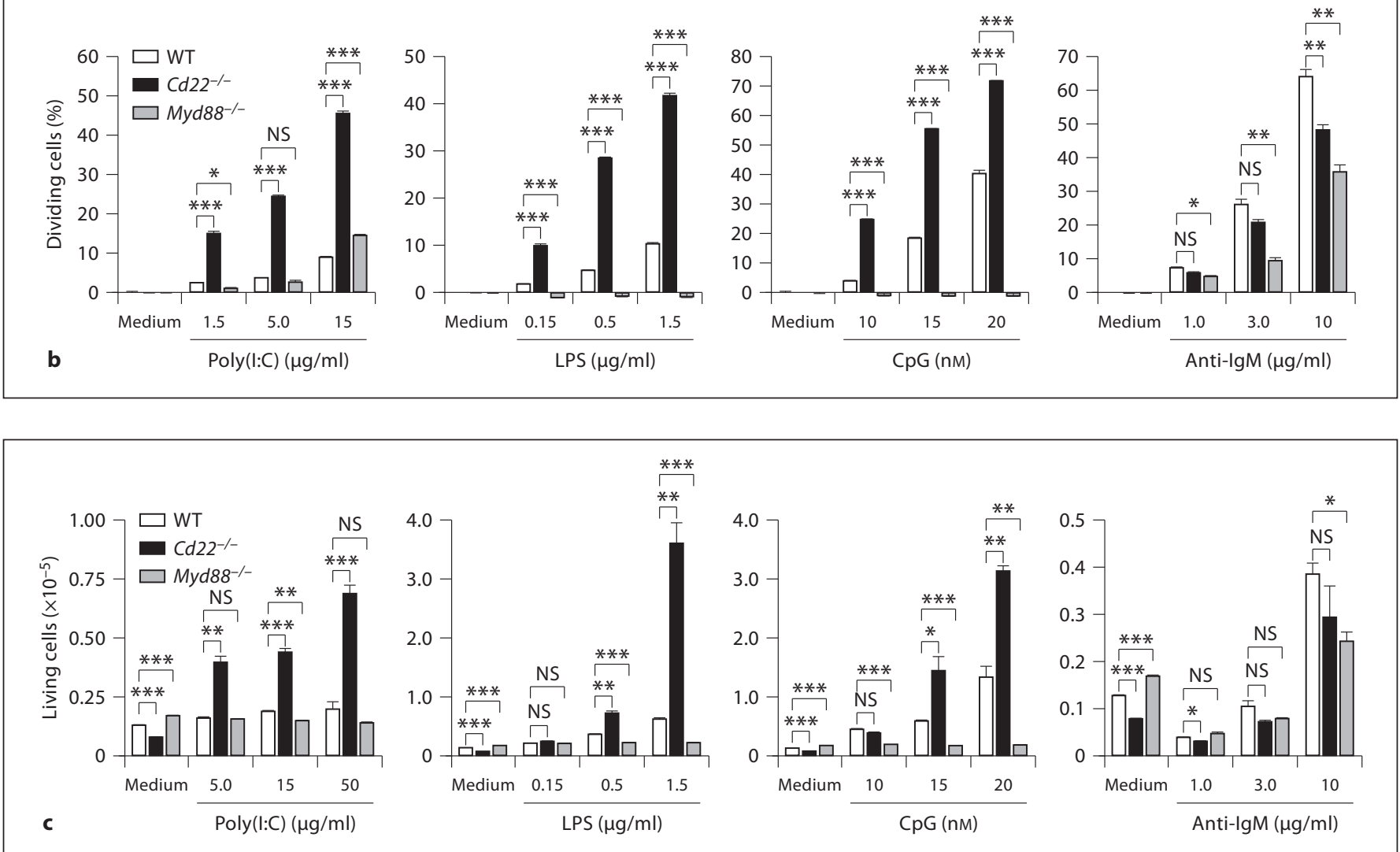

Fig. 1. CD22 deficiency causes hyperproliferation of B cells in response to TLR ligands. a CFSE-labeled B cells were cultured for 3 days in the absence (black) or presence (gray) of $5.0 \mu \mathrm{g} / \mathrm{ml}$ poly(I:C), $1.5 \mu \mathrm{g} / \mathrm{ml}$ LPS, $15 \mathrm{nM} \mathrm{CpG}$ and $3.0 \mu \mathrm{g} / \mathrm{ml}$ anti-IgM. Cells were analyzed by flow cytometry. $\mathbf{b}$ Percentage of dividing cells from 2 days' culture subtracted with the value in the absence of stimulation are shown. Statistical analyses were performed by Student's t test. ${ }^{*} \mathrm{p}<0.05 ;{ }^{* *} \mathrm{p}<0.01 ;{ }^{* *} \mathrm{p}<0.001$. c Living cell number in the wells of 3 days' culture is shown. Before the analysis, $1.0 \times 10^{4}$ of beads was added to the culture well. Cells were then harvested and analyzed by flow cytometry. Living cell number was calculated by the formula: living cell number in the well $=$ the number of living cells acquired $\times$ number of beads acquired $/ 1.0 \times 10^{4}$. Data are representative of 3 independent experiments with similar results. 

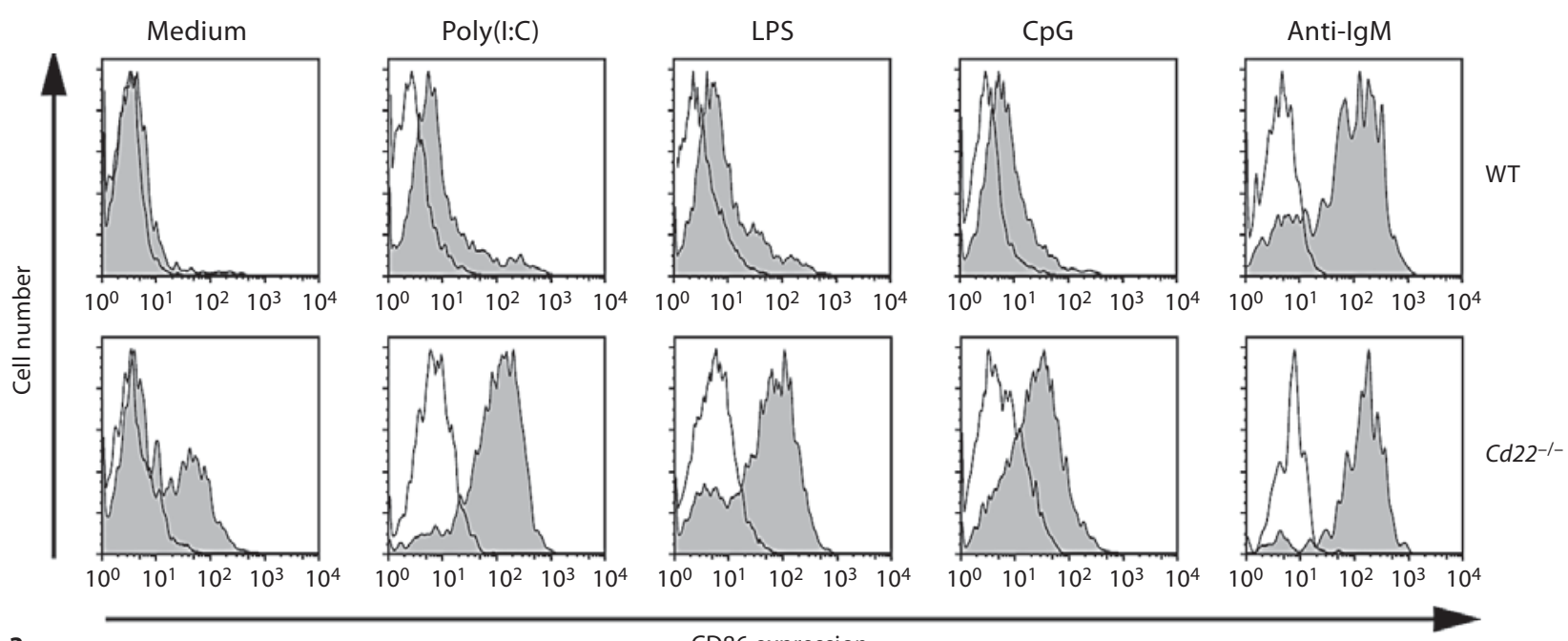

CD86 expression
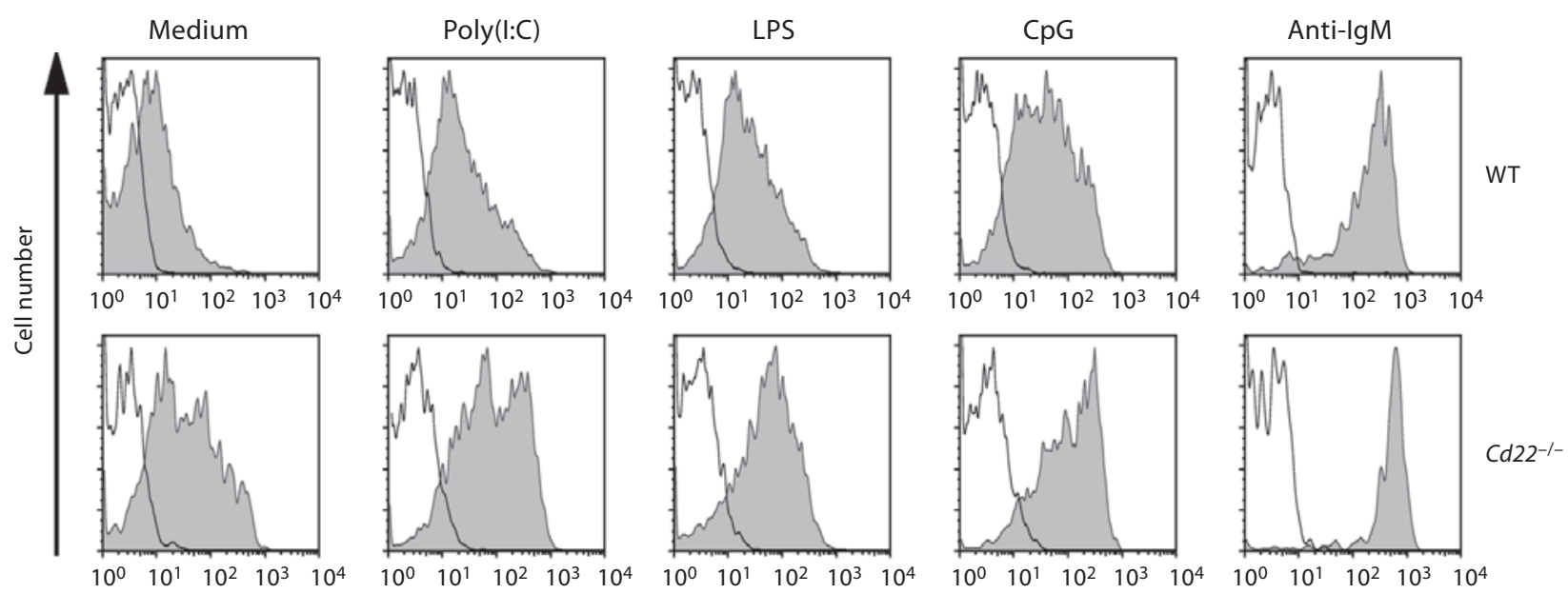

b

MHC class II expression

Fig. 2. Augmented CD 86 and class II induction in $\mathrm{Cd} 22^{-/-} \mathrm{B}$ cells in response to TLR ligands. WT and $C d 22^{-/-} \mathrm{B}$ cells were stimulated for 2 days with $10 \mu \mathrm{g} / \mathrm{ml}$ poly(I:C), $0.15 \mu \mathrm{g} / \mathrm{ml}$ LPS, $7.5 \mathrm{nM}$ $\mathrm{CpG}$ and $0.3 \mu \mathrm{g} / \mathrm{ml}$ anti-IgM. Then cells were harvested and stained with anti-CD86 (a) or anti-MHC class II I-A ${ }^{\mathrm{b}}$ (b) (gray) or isotype-matched control Ab (black). Stained cells were washed and analyzed by flow cytometry. Data are representative of 3 independent experiments with similar results. signaling in the $C d 22^{-/-} \mathrm{J} 2-44 \mathrm{~B}$ cell line [21]. MHC class II induction by TLR ligands was reproducibly suppressed by expression of CD22 (fig. 4a; online suppl. fig. 2), consistent with a direct effect of CD22 on TLR signaling. We next sought to demonstrate the impact of CD22 on TLR signaling on WT B cells by antibody-mediated seques- tration of $\mathrm{CD} 22$, an approach used to demonstrate the importance of $\mathrm{CD} 22$ co-localization on the regulation of $\mathrm{BCR}$ signaling [22]. In wells containing immobilized anti-CD22 mAb, WT B cells exhibited enhanced proliferation in response to TLR ligands relative to cells exposed to wells with immobilized isotype control Ab (fig. $4 \mathrm{~b}$; 
Fig. 3. TLR expression in $C d 22^{-/-} \mathrm{B}$ cells is not significantly different from that of WT B cells. a Total RNA was extracted from isolated WT and Cd22-/- B cells. Expression of TLR 3 and 4 was examined by quantitative real-time PCR. Expression levels were normalized to $\beta$-actin. Statistical analyses were performed by Student's $t$ test. b Isolated B cells were fixed, permeabilized and then stained with anti-TLR9 Ab followed by $R$-phycoerythrin-labeled secondary Ab. Stained cells were washed and analyzed by flow cytometry. Geometric mean fluorescence intensity (MFI) of $\mathrm{Cd} 22^{-/-} \mathrm{B}$ cells relative to WT is shown. Statistical analyses were performed by Student's $t$ test. Data are representative or means of 3 independent experiments with similar results.

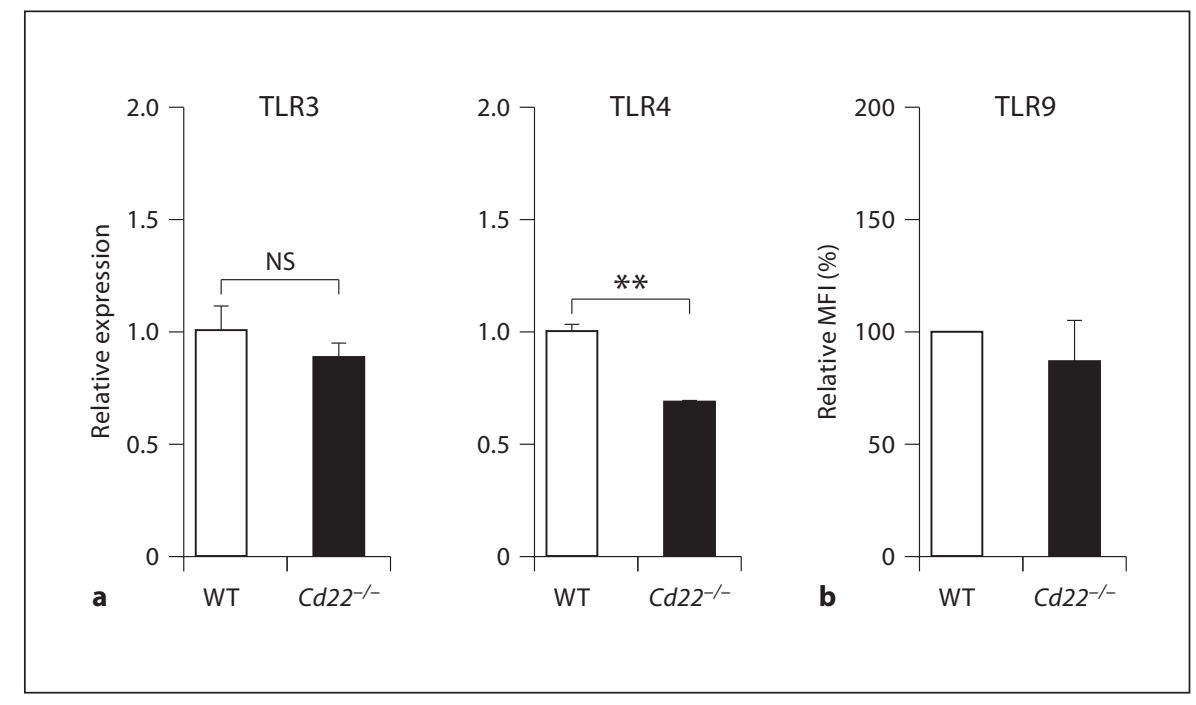

online suppl. fig. 3), suggesting sequestration of CD22 from TLRs 4 and 9 by the immobilized anti-CD22 $\mathrm{mAb}$ augments proliferation by TLR ligands. Furthermore, using a TLR4 reporter cell line, we found that the transcriptional activity of NF- $\kappa \mathrm{B}$, which is a hallmark of TLR signaling [20], is well suppressed by the ectopic expression of CD22 in TLR4 reporter cells (fig. 4c; online suppl. fig. 4), suggesting that CD22 has an intrinsic inhibitory effect on NF- $\kappa B$ activation. Thus, three independent approaches suggest that CD22 directly regulates TLR signaling in $\mathrm{B}$ cells. To gain further insight into the mechanism of negative regulation of TLR signaling by CD22, we tested whether hallmarks of TLR signaling pathways including $\mathrm{p} 38$, JNK and NF- $\mathrm{\kappa B}$ signaling were augmented in $C d 22^{-/-} \mathrm{B}$ cells. We found that $\mathrm{p} 38$ and JNK phosphorylation was similar in $C d 22^{-/-}$and WT B cells (online suppl. fig. 5). While the I $\kappa \mathrm{B} \alpha$ degradation which results in the release of NF- $\kappa \mathrm{B}$ dimers into nucleus, preferably p65/p50, is not altered in $C d 22^{-/-} \mathrm{B}$ cells (online suppl. fig. 4), we found that the repertoire of active NF- $\mathrm{KB}$ subunits in $\mathrm{Cd} 22^{-/-} \mathrm{B}$ cells in both resting and CpG-stimulated conditions was significantly biased to the nonclassical NF- $\kappa \mathrm{B}$ pathways revealed by higher DNA-binding activity of p50, p52 and RelB than that in WT B cells (fig. 5a) [23]. With respect to inhibitory regulators of TLR activation, we found that induction of SOCS1 and 3, known as suppressors of TLR signaling [12-14], was impaired in $C d 22^{-/-} \mathrm{B}$ cells (fig. 5b). It is interesting to speculate that altered NF- $\mathrm{KB}$ activation caused by $\mathrm{CD} 22$ deficiency results in poor induction of SOCS1 and 3, leading to the prolonged TLR signaling, which in turn results in the augmented phenotype of Cd22/- B cells.

Our results suggest that CD22 is a constitutive negative regulator of TLR-activated signaling pathways that are distinct from and not mediated by the BCR [7]. Recently, Jellusova et al. [18] also reported the augmented proliferation of $\mathrm{Cd}_{22} 2^{-/-}$and Siglecg ${ }^{-/-} \mathrm{B}$ cells in response to TLR ligand. Results presented here suggest that the augmented TLR signaling in $C d 22^{-/-} \mathrm{B}$ cells is a consequence of the loss of constitutive negative regulation of TLR signaling by CD22 in B cells. This conclusion is relevant to the observation that mice carrying a TLR7 gene duplication (Y-linked autoimmune accelerator) exhibit an anti-DNA antibody autoimmune phenotype when crossed into a $\mathrm{Cd} 22^{+/-}$background [24].

Our data document that CD22 is a regulator of receptors that mediate both adaptive and innate immune responses of the B cell. In its regulation of the BCR, CD22 is believed to exert its activity through close physical association $[3,4,25]$. Since sequestration of CD22 augmented LPS activation of TLR4 signaling, this is also likely the case for CD22 regulation of TLRs. In this regard, since TLRs are located on both the cell surface (TLR4) and endosomal compartments (TLR3 and 9), CD22 regulation of TLRs might be tied to its constitutive endocytic activity, placing it both on the cell surface and in endosomal compartments $[19,26]$.

CD22 is a member of the Siglec family, which comprises 14 human and 9 murine members that are predominantly expressed on leukocytes that mediate the adaptive and innate arms of immune function [1]. A few reports 

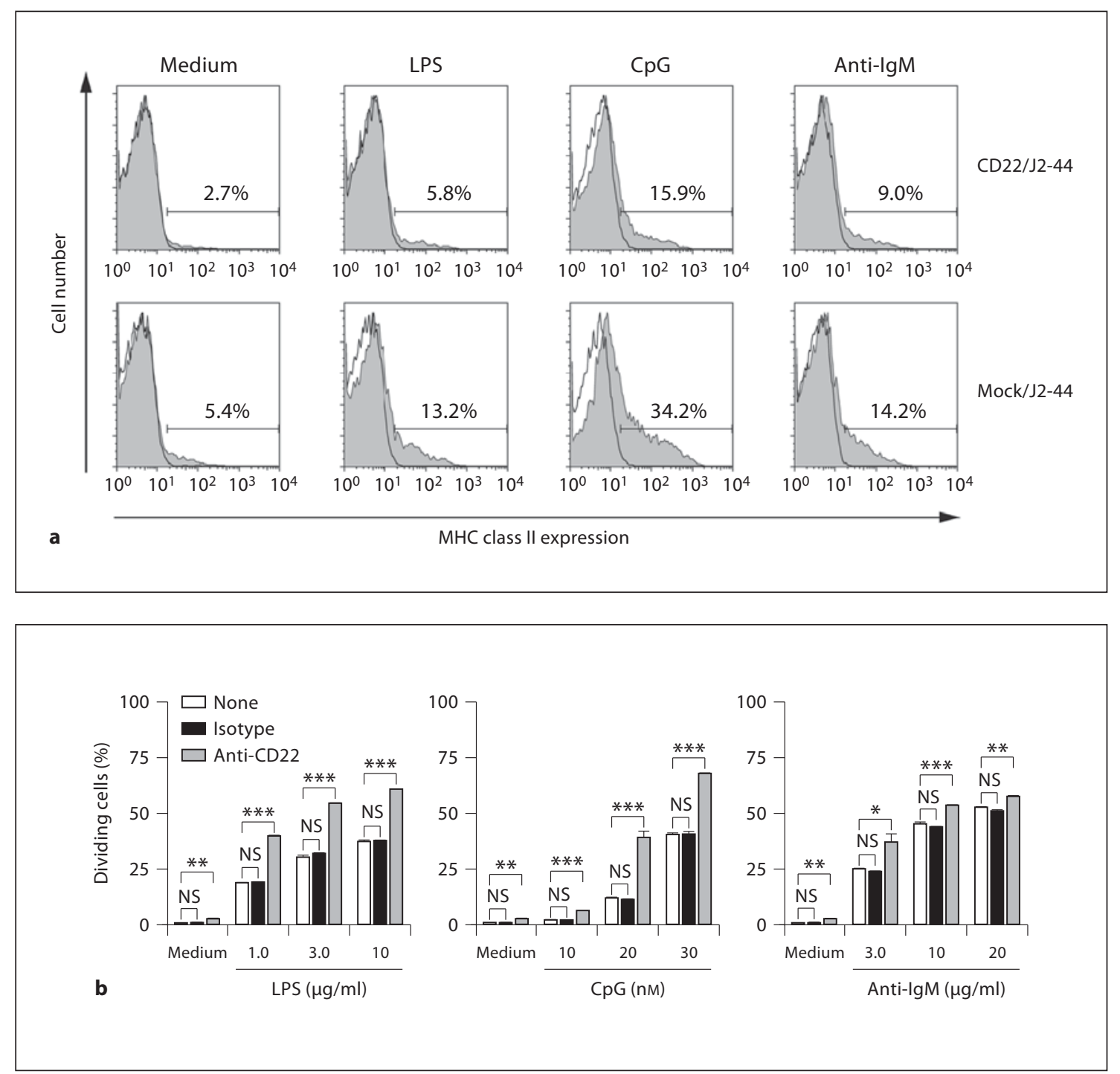

Fig. 4. CD22 negatively regulates TLR signaling in B cells. a Expression of CD22 in $\mathrm{J} 2-44 \mathrm{Cd} 22^{-/-} \mathrm{B}$ cells suppresses induction of MHC II by TLR ligands. J2-44 cells were retrovirally transduced with mouse CD22 and stimulated with $3.0 \mu \mathrm{g} / \mathrm{ml} \mathrm{LPS}, 15 \mathrm{nM} \mathrm{CpG}$ and $3.0 \mu \mathrm{g} / \mathrm{ml}$ anti-IgM. After 2 days, MHC class II expression was examined by flow cytometry as in figure 2. b Sequestration of CD22 by immobilized anti-CD22 Ab enhances B cell proliferation by TLR ligands. CFSE-labeled WT B cells were stimulated with soluble LPS, CpG and anti-IgM in the presence of immobilized anti-CD22 mAb or isotype-matched control Ab. After 2 days, cells were analyzed by flow cytometry. c Expression of CD22 inhibits NF- $\kappa \mathrm{B}$ activation in a TLR4 reporter cell line. mTLR4/ HEK293 cells were transfected with NF- $\kappa$ B-inducible AP and mCD22 or empty vector and stimulated with $10 \mu \mathrm{g} / \mathrm{mL}$ of LPS. The culture supernatant was incubated with the AP substrate at $37^{\circ} \mathrm{C}$. Then the enzymatic activity was measured by the absorbance of $405 \mathrm{~nm}$. Background absorbance from culture supernatant only was subtracted. Statistical analyses were performed by Student's t test. Data are representative of 2 or 3 independent experiments with similar results.

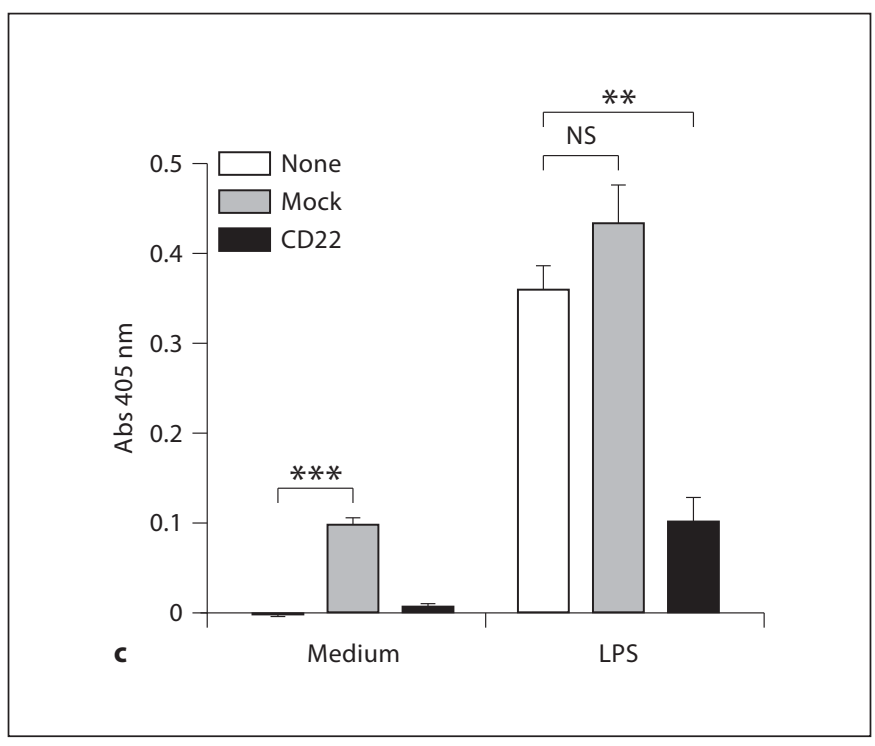




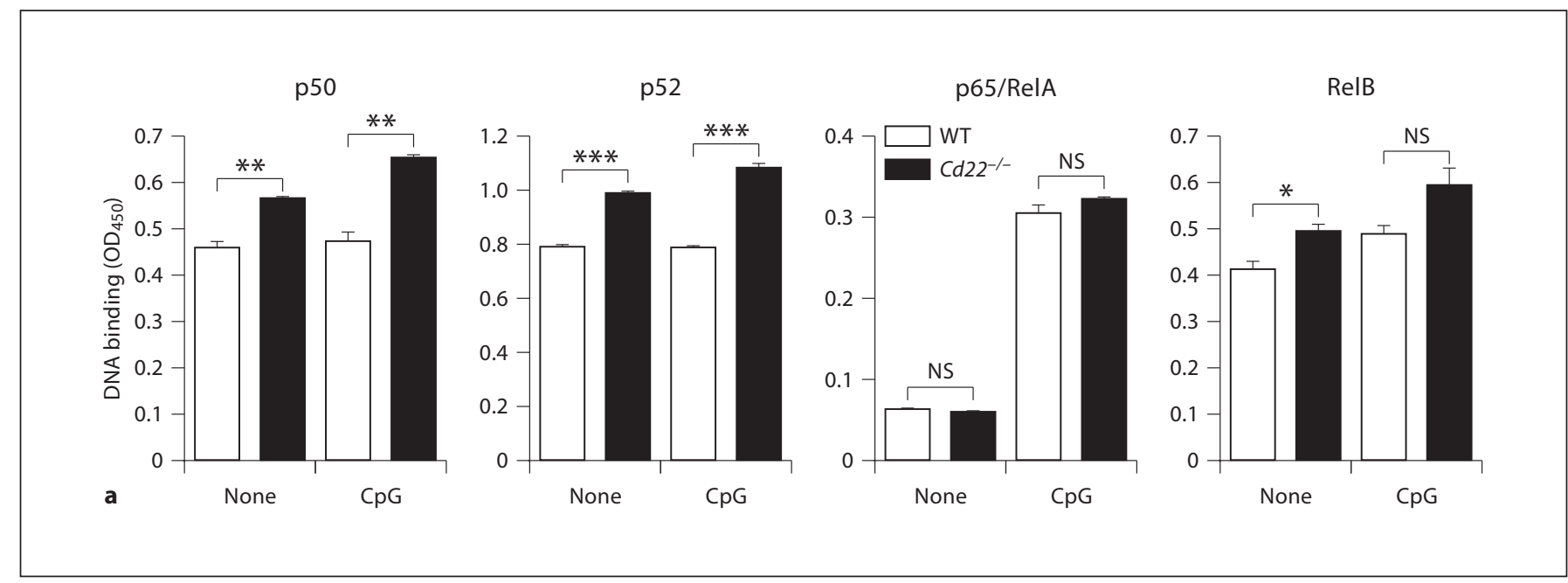

Fig. 5. Signaling analysis of $C d 22^{-/-} \mathrm{B}$ cells. a CD22 deficiency results in different spectrum of NF- $\kappa \mathrm{B}$ activation. DNA binding activity of the NF- $\mathrm{B}$ subunits, p50, p52, p65 and RelB in the nuclear extracts from WT and $C d 22^{-/-} \mathrm{B}$ cells was assayed by ELISA using oligonucleotides containing the NF- $\mathrm{\kappa B}$-binding site and specific antibodies to each subunit. $\mathbf{b}$ Impaired induction of SOCS1 and 3 in $C d 22^{-/-}$B cells upon CpG stimulation. Total RNA was extracted from $1.0 \times 10^{7}$ of B cells from WT or $C d 22^{-/-} \mathrm{B}$ cells stimulated with $250 \mathrm{nM} \mathrm{CpG}$ for 3 h or unstimulated. Expression of SOCS1 and 3 was examined by quantitative real-time PCR. Expression levels were normalized to $\beta$-actin. Statistical analyses were performed by Student's t test. Data are representative of 2 independent experiments with similar results.

suggest that other Siglecs might regulate TLRs. Recently Siglec-E and $\mathrm{H}$ were found to regulate cytokine production in response to TLR ligand in macrophages and plasmacytoid dendritic cells, respectively $[27,28]$. Similarly, ectopic expression of Siglec-9, 11 and 14 in macrophages has also been observed to influence cytokine production in response to TLR ligands [29-31]. Thus as shown here for CD22, it is likely that other Siglecs will be found to regulate TLR signaling in the cells that express them, and that this will prove to be a general property of the Siglec family.

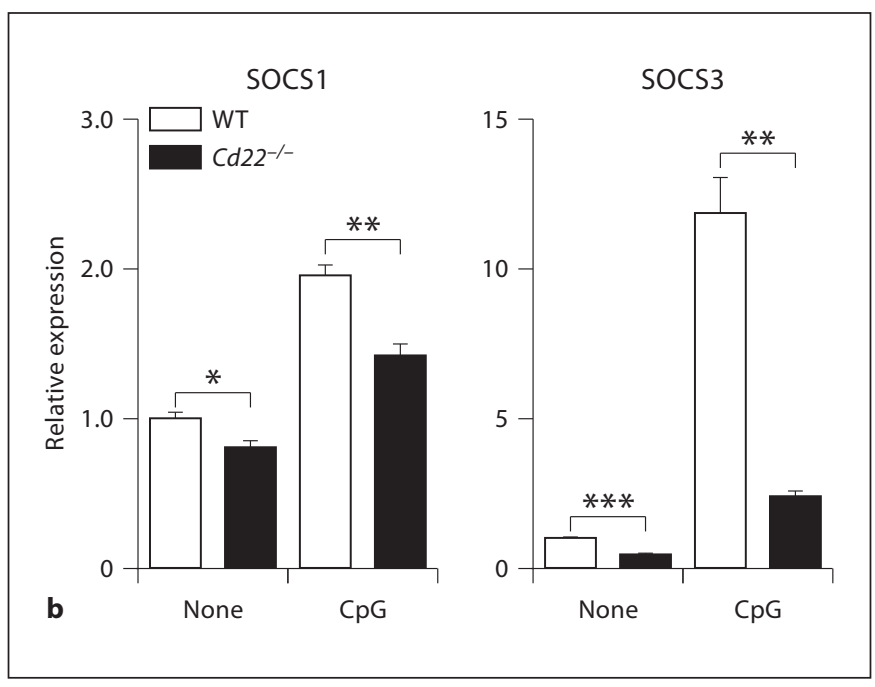

\section{Acknowledgements}

We would like to thank Bao Duong, Bruce Beutler, David Nemazee, Henry Wortis, Hua Tian, Katharina Brandl, Kazuo Yamamoto, Lars Nitschke, Takayuki Ota, Toshio Kitamura for mice,

reagents and insightful discussions, the flow cytometry core facility in The Scripps Research Institute for cell sorting, and Anna Tran-Crie for her help in manuscript preparation. C.R. was supported by an EMBO long-term fellowship. This work was supported by NIH grant AI050143 to J.C.P.

\section{Disclosure Statement}

The authors declare no competing financial interests. 


\section{References}

$>1$ Crocker PR, Paulson JC, Varki A: Siglecs and their roles in the immune system. Nat Rev Immunol 2007;7:255-266.

$>2$ Walker JA, Smith KG: CD22: an inhibitory enigma. Immunology 2008;123:314-325.

$>3$ Duong BH, Tian H, Ota T, Completo G, Han S, Vela JL, Ota M, Kubitz M, Bovin N, Paulson J, Nemazee D: Decoration of T-independent antigen with ligands for CD22 and Siglec-G can suppress immunity and induce B cell tolerance in vivo. J Exp Med 2010;207: 173-187, S171-S174.

4 Courtney AH, Puffer EB, Pontrello JK, Yang ZQ, Kiessling LL: Sialylated multivalent antigens engage CD22 in trans and inhibit B cell activation. Proc Natl Acad Sci USA 2009; 106:2500-2505.

$\checkmark 5$ Lanoue A, Batista FD, Stewart M, Neuberger MS: Interaction of CD22 with $\alpha 2,6$-linked sialoglycoconjugates: innate recognition of self to dampen B cell autoreactivity? Eur J Immunol 2002;32:348-355.

-6 Meyer-Bahlburg A, Rawlings DJ: B cell autonomous TLR signaling and autoimmunity. Autoimmun Rev 2008;7:313-316.

$>7$ Patterson HC, Kraus M, Kim YM, Ploegh H, Rajewsky K: The B cell receptor promotes B cell activation and proliferation through a non-ITAM tyrosine in the Igalpha cytoplasmic domain. Immunity 2006;25:55-65.

-8 Pasare C, Medzhitov R: Control of B-cell responses by Toll-like receptors. Nature 2005; 438:364-368.

>9 Gavin AL, Hoebe K, Duong B, Ota T, Martin C, Beutler B, Nemazee D: Adjuvant enhanced antibody responses in the absence of toll-like receptor signaling. Science 2006 314:1936-1938.

$>10$ Eckl-Dorna J, Batista FD: BCR-mediated uptake of antigen linked to TLR9 ligand stimulates B-cell proliferation and antigen-specific plasma cell formation. Blood 2009;113: 3969-3977.

11 Marshak-Rothstein A: Toll-like receptors in systemic autoimmune disease. Nat Rev Immunol 2006;6:823-835.
12 Naka T, Fujimoto M, Tsutsui H, Yoshimura A: Negative regulation of cytokine and TLR signalings by SOCS and others. Adv Immunol 2005;87:61-122.

13 Dalpke AH, Opper S, Zimmermann S, Heeg $\mathrm{K}$ : Suppressors of cytokine signaling (SOCS) 1 and SOCS-3 are induced by CpG-DNA and modulate cytokine responses in APCs. J Immunol 2001;166:7082-7089.

14 Rothlin CV, Ghosh S, Zuniga EI, Oldstone $\mathrm{MB}$, Lemke G: TAM receptors are pleiotropic inhibitors of the innate immune response. Cell 2007;131:1124-1136.

15 Nitschke L, Carsetti R, Ocker B, Kohler G, Lamers MC: CD22 is a negative regulator of B-cell receptor signalling. Curr Biol 1997;7: 133-143.

16 Sato S, Miller AS, Inaoki M, Bock CB, Jansen PJ, Tang ML, Tedder TF: CD22 is both a positive and negative regulator of $\mathrm{B}$ lymphocyte antigen receptor signal transduction: altered signaling in CD22-deficient mice. Immunity 1996;5:551-562.

17 Otipoby KL, Andersson KB, Draves KE, Klaus SJ, Farr AG, Kerner JD, Perlmutter RM, Law CL, Clark EA: CD22 regulates thymus-independent responses and the lifespan of B cells. Nature 1996;384:634-637.

18 Jellusova J, Wellmann U, Amann K, Winkler TH, Nitschke L: CD22 $\times$ Siglec-G doubledeficient mice have massively increased B1 cell numbers and develop systemic autoimmunity. J Immunol 2010;184:3618-3627.

19 Shan D, Press OW: Constitutive endocytosis and degradation of CD22 by human B cells. J Immunol 1995;154:4466-4475.

20 Takeda K, Akira S: TLR signaling pathways. Semin Immunol 2004;16:3-9.

21 Jin L, McLean PA, Neel BG, Wortis HH: Sialic acid binding domains of CD22 are required for negative regulation of $\mathrm{B}$ cell recep tor signaling. J Exp Med 2002;195:11991205 .

22 Doody GM, Justement LB, Delibrias CC, Matthews RJ, Lin J, Thomas ML, Fearon DT: A role in $\mathrm{B}$ cell activation for $\mathrm{CD} 22$ and the protein tyrosine phosphatase SHP. Science 1995;269:242-244.
23 Chen LF, Greene WC: Shaping the nuclear action of NF- $\kappa$ B. Nat Rev Mol Cell Biol 2004; 5:392-401.

-24 Mary C, Laporte C, Parzy D, Santiago ML, Stefani F, Lajaunias F, Parkhouse RM, O’Keefe TL, Neuberger MS, Izui S, Reininger L: Dysregulated expression of the $\mathrm{Cd} 22$ gene as a result of a short interspersed nucleotide element insertion in $\mathrm{Cd} 22 \mathrm{a}$ lupus-prone mice. J Immunol 2000;165:2987-2996.

25 Hokazono Y, Adachi T, Wabl M, Tada N, Amagasa T, Tsubata T: Inhibitory coreceptors activated by antigens but not by anti-Ig heavy chain antibodies install requirement of costimulation through CD40 for survival and proliferation of B cells. J Immunol 2003; 171:1835-1843.

26 Tateno H, Li H, Schur MJ, Bovin N, Crocker PR, Wakarchuk WW, Paulson JC: Distinct endocytic mechanisms of CD22 (Siglec-2) and Siglec-F reflect roles in cell signaling and innate immunity. Mol Cell Biol 2007;27: 5699-5710.

27 Boyd CR, Orr SJ, Spence S, Burrows JF, Elliott J, Carroll HP, Brennan K, Ni Gabhann J, Coulter WA, Jones C, Crocker PR, Johnston JA, Jefferies CA: Siglec-E is up-regulated and phosphorylated following lipopolysaccharide stimulation in order to limit TLR-driven cytokine production. J Immunol 2009;183: 7703-7709.

28 Blasius A, Vermi W, Krug A, Facchetti F, Cella M, Colonna M: A cell-surface molecule selectively expressed on murine natural interferon-producing cells that blocks secretion of interferon- $\alpha$. Blood 2004;103:4201-4206.

29 Ando M, Tu W, Nishijima K, Iijima S: Siglec-9 enhances IL-10 production in macrophages via tyrosine-based motifs. Biochem Biophys Res Commun 2008;369:878-883.

30 Yamanaka M, Kato Y, Angata T, Narimatsu $\mathrm{H}$ : Deletion polymorphism of SIGLEC14 and its functional implications. Glycobiology 2009;19:841-846.

31 Wang Y, Neumann H: Alleviation of neurotoxicity by microglial human Siglec-11. J Neurosci 2010;30:3482-3488. 